\title{
Sanitary Sewer's Infrastructure in the Brazilian Semiarid Areas and its Consequences for People's Health: The Case of the City of Santo Estevão-BA
}

\author{
Oliveira Lusanira Nogueira Aragão de, ${ }^{1 *}$ Oliveira Alarcon Matos de, ${ }^{2}$ Santos Rosângela Leal $^{1}$ \\ ${ }^{1}$ Technology Department, State University of Feira de Santana, Brazil \\ ${ }^{2}$ Municipal Secretary of Planning, Municipal Government of Feira de Santana, Brazil
}

\begin{abstract}
This research aims to Identify the areas with higher shortcoming in distribution of sanitation's services, especially those related to the sanitary sewer and the main consequences to people's health. The study's field bounded three neighborhoods from Santo Estevão city (Alto do Porrão, Mutirão and Pau de Vela). For data collection, geoprocessing was necessary through the Global Positioning System (GPS), Cartography and Geographical Information System in order to demarcate the points relating to the water's spatial distribution. Therefore, the areas with a significant frequency of diseases due to the lack of sanitary sewer were described in order to build thematic maps. The methodological procedure used was the case report because of its enabling nature to investigate the phenomenon here described, and also considering that city's population was directly involved with the research. For data collecting, it was used the application form with people from the bounded areas. There was also the collecting of data and information in public institutions and agencies, among them the Santo Estevão Municipal Government, Company of Water and Sanitation from Bahia state, Statistics and Information Oversight and Brazilian Institute of Geography and Statistics.
\end{abstract}

Keywords: Sanitary sewer, Santo estevão, Life quality

\section{Introduction}

Sanitation is one of the main urban infrastructure systems, and according to Sanitation Atlas, ${ }^{1}$ it "constitutes a group of actions that aims at the modification of environmental conditions with the objective of preventing pathogenic vectors spread and promoting public health and population's well-being". From this concept, we point out two basic conditions:

1) Sanitation necessarily modifies the environmental features

2) This modification has as objectives to promote health and to prevent diseases
We can understand then that the inhabitants' life quality is directly associated to the treatment of water of using, the disposed water, the produced waste and the hygienic conditions. Sanitation is a serious issue, mainly in urban areas from the poorest countries that had a later and fast urbanization process together with the regional and social inequality.

According to Roque, "it is spent millions of dollars on health care's defrayal that could be reduced to half if we have a sanitation's infrastructure operating as prevention". A disabled sanitary infrastructure expresses a clear interface with people's life and health conditions in the underdeveloped countries, where infectious dis-

\begin{tabular}{|l|l|}
\hline Quick Response Code: & *Corresponding author: Oliveira Lusanira Nogueira Aragão de, Technology Department, \\
State University of Feira de Santana, Brazil \\
Received: 24 November, $2020 \quad$ Published: 14 December, 2020 \\
Citation: Oliveira LNA, Oliveira AM, Santos RL. Sanitary Sewer's Infrastructure in the Brazil- \\
ian Semiarid Areas and its Consequences for People's Health: The Case of the City of Santo \\
Estevão-BA. Glob Scient Res Env Sci. 2020;1(1):1-9. DOI: 10.53902/GSRES.2020.01.000504
\end{tabular}


eases keep being an important cause of morbidity and mortality. In 2007, data from the National Research for Domicile's Samples pointed out that around $30 \%$ of domiciles did not have an appropriate sanitary sewer, this is to say that the sewer is not connected to a collecting system or a septic cesspool. Sewers and human waste can cause serious issues to environment and to human's health. Human waste can be the conduit of pathogenic germs from many diseases, as infectious diarrhea, tapeworm infection, schistosomiasis, typhoid fever, among others. It is coherent to stand out that due to the lack of practical actions over sanitation and health education matters, a significant percentage of population throw their waste directly in the soil and in the water supply sources, what brings favorable conditions to spread diseases.

The research field was the urban area of Santo Estevão city (Figure 1), situated in Bahia state. Santo Estevãoen compasses a total area of $141.543 \mathrm{mi}^{2}$, an area which has a total population of 47,880 according to 2012 Census. The city is located next to BR 116 highway, in Feira de Santana's micro-region, on Paraguaçu Valley and it is surrounded by the cities of Ipecaetá, Rafael Jambeiro, Antônio Cardoso, Castro Alves and Cabaceiras do Paraguaçu.

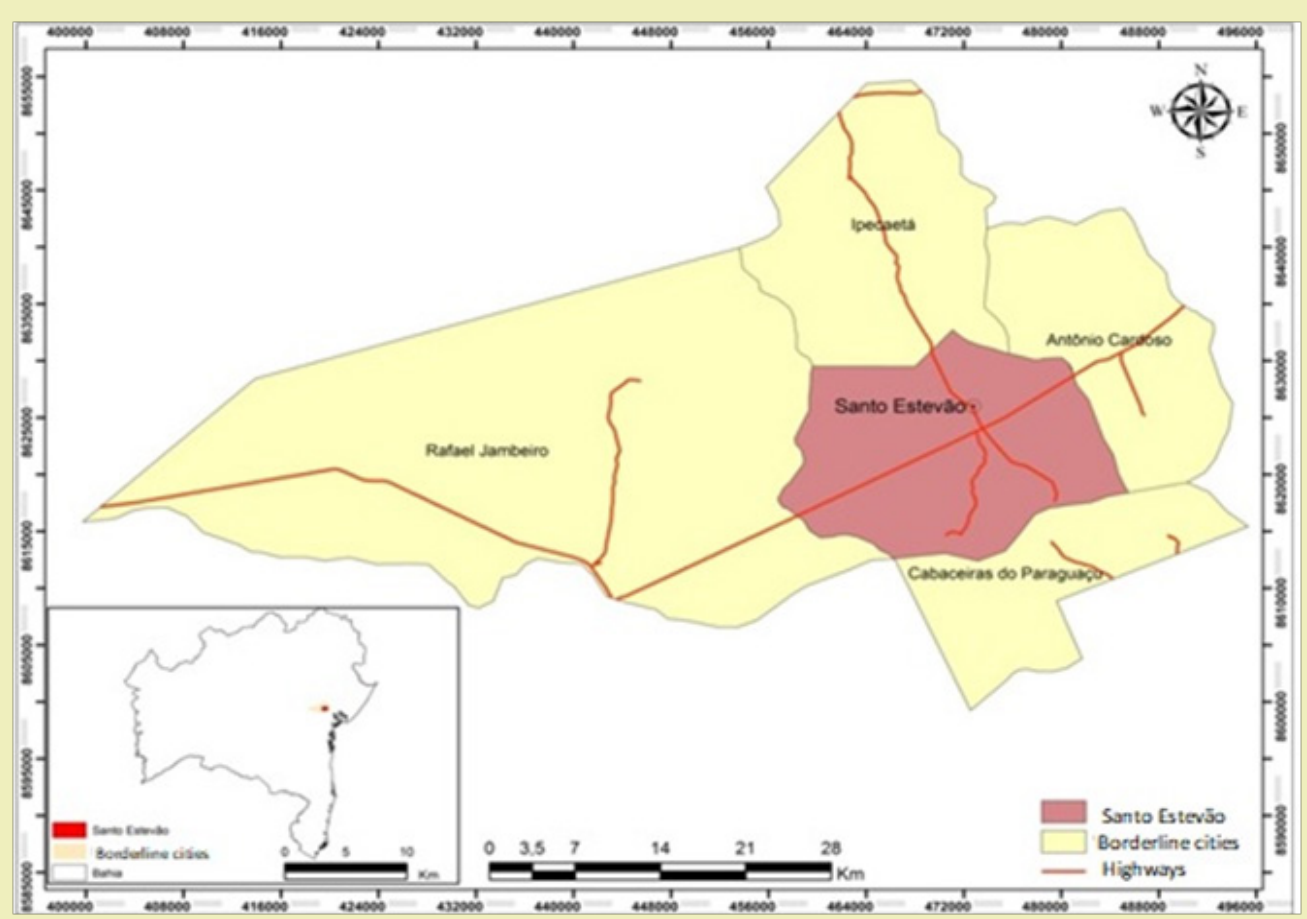

Figure 1: Localization Map of the Survey's Area.

Source: CARELLI, 2013.

The coordinates of the city are about $12^{\circ} 25^{\prime} 49^{\prime \prime} \mathrm{S}$ and 39015'05' 'W, with approximately an elevation of 793 feet above sea level. Geographically, the city is formed by two geological structures, classified as Pediplano Sertanejo and Tabuleiro. The first formation is considered a typical area from the northeastern hinterland, with a sharp dry season and a concave convex design. The second formation is located in the city's center, with a Cenozoic coverage and residual nature, where urban population is prevailing due to its leveled aspect. ${ }^{3}$ The prevailing climate from the field's research is the semiarid, characterized by low humidity and rainindex with an average rainfall between 200 and $400 \mathrm{~mm}$ by year. ${ }^{4}$ The chosen spatial background refers to the three areas of the city's urban perimeter: Alto do Porrão, Mutirão and Pau de Vela, where serious issues of sanitation, mainly in sanitary sewer, become a serious causer of environment damage and, as consequence, it affects public health. Therefore, the main objective of research is identifying areas where distribution of sanitation service is unsatisfying, especially when it is related to sanitary sewer and its main consequences for people's health.

\section{Methodology}

For research's development, it was firstly done an exhaustive bibliographical survey about the investigated phenomenon and data and information collection in public institutions and agencies, among them Santo Estevão Municipal Government, Company of Water and Sanitation from Bahia state, Statistics and Information Oversight, and Brazilian Institute of Geography and Statistics. After that, it was started the geoprocessing step through the Global Positioning System (GPS) and Cartography and Geographical Information System in order to demarcate the points related to water distribution, waste collection and sanitary sewer. Then, it was aimed to point out the areas where disease frequency could be caused by inadequate sewage. Later, this information was used to elaborate thematic Tables and maps.

\section{Types of studying}

Santana ${ }^{5}$ says that a method is a group of procedures and techniques implied in an ordered and systematic way in order to ob- 
tain a better result in a task. Thus, through a method it is possible to comprehend a reality, to produce an object, and even to develop some procedures. Following this idea, this research is understood as descriptive, once it aims at characterizing a population or an investigated phenomenon making a connection between their variables. In regard to the methodological procedure applied on research, the case study comes out as the most appropriate to look into the examined phenomenon, once it was directly attended to Santo Estevão's community, and data's selection, collection, analysis and interpretation.

\section{People Involved on Research}

As it is a case study research, people selected for analysis in all its scope were the urban ones. The spatial highlighting will consider the territorial boundaries of their areas' division, directly associated to the dynamic from the examined phenomenon. It is worth mentioning that the spatial highlighting reflects not only the socioeconomic and environmental conditions of people, but also their life quality. The selected areas were Alto do Porrão, Mutirão and Pau de Vela (Figure 2). All of them are considered peripheral and low-income areas, however each of them has its own features.

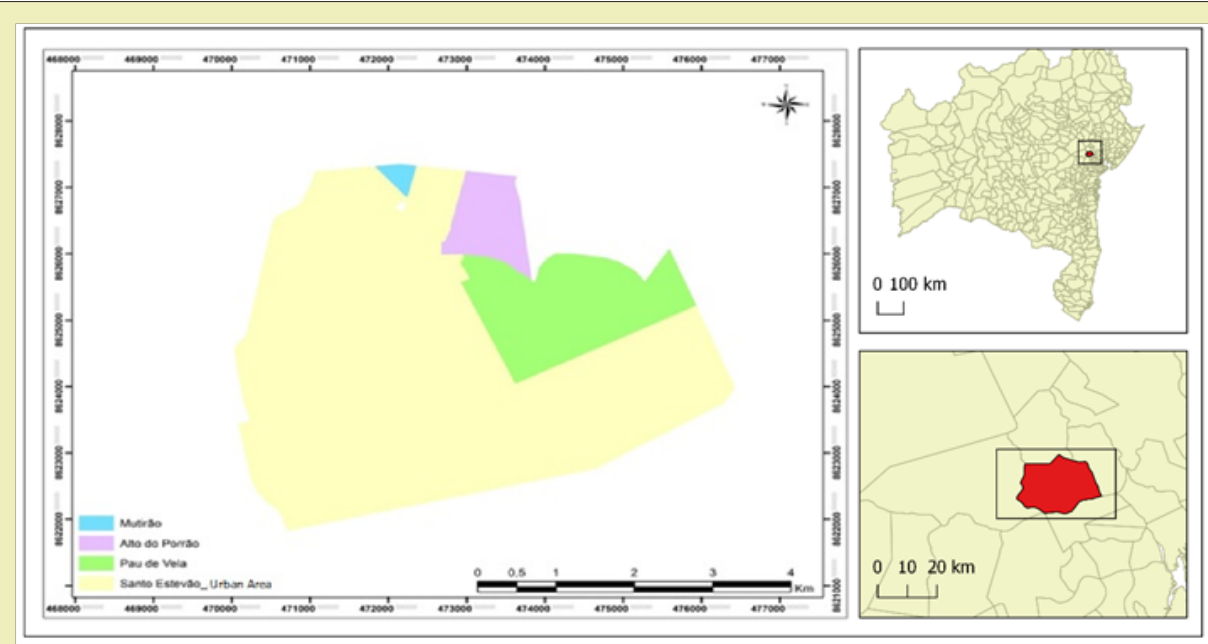

Figure 2: Localization Map of the Examined Areas: Mutirão, Alto do Porrão and Pau de Vela.

Source: Bahia, 2003. Adapted by: CARELLI, L., 2014.

Alto do Porrão housing process began in the 1990s as the early residents invaded the area and started to build their houses. Because it is a hillside area and likely to sliding - as the example of one that occurred in the end of the 1990s, the municipal government expropriated it. But, due to the lack of choice, people went back to live there. In relation to Alto do Porrão's physical infrastructure, some services are provided, as the daily collection of solid waste, and the water supply by the Company of Water and Sanitation from Bahia state. In addition, the streets are paved, the houses have electricity and there is a health center (Antonieta Copellode Cerqueira Health Center) that addresses the residents of Alto do Porrão and Mutirão.

Mutirão was planned by the municipal government to be a housing area. It is the only, among the three regions examined, to provide all the sanitation's services: water supply, solid waste collection, sewage system, and storm drain, besides of possessing a necessary infrastructure to cater to people's demand. However, the quantity and the quality of these services are often short of residents' necessities. The last selected area for research's development, Pau de Vela, was only incorporated to urban zone in the 2000 Census. At present, there are some features in Pau de Vela very similar to countryside practices, such as the cattle breeding. Just as in Alto do Porrão and Mutirão, the region has basic services to cater people's demand, except for the sewage system. Besides its inhabitants, Pau de Vela's health center (Antonieta Alves Araújo
Oliveira Health Center) also addresses to Conga's population, a near rural area.

\section{Data Collection Tool and Technique}

In search of identifying aspects and information related to sanitary sewage, it was elaborated an application with closed questions. An application is a research instrument characterized for the direct contact between the researcher and the informer. The difference between questionnaire and application is that the first one is filled out by the person who is interviewed, while the second one is filled out by the researcher. One of the advantages of using the application is the possibility of discussion between the informer and the researcher, it allows the topic to be rephrased, the elucidation of some points, and the explanation of questions. In other words, the application can be adjusted to each informer experience and comprehension. That is why the application can encompass more complex matters than the questionnaire. ${ }^{5}$ Another advantage of application use is the fact that the informer does not need to know how to read or write, while as disadvantage, he/she cannot check what was written by the researcher. ${ }^{5}$ Since it is a survey that deal with human beings, the project needed to be registered at Plataforma Brasil and then it was directed to the Committee of Ethic in Survey from the State University of Feira de Santana. After the assessment and acceptance by the Committee, a protocol number of Submission's Certificate to Ethical Assessment was generated, which is 
11346612.3.0000.0053. The application was carried out after the target population to sign a clear term of agreement, assuming they were aware of research's objective. The application was used with the purpose of requiring data, and comprehending how the local people figure out the sanitary sewage. The number of samples represents the total amount of applications in the residences of the examined area (Table 1).

Table 1: Number of application's samples by domicile.

\begin{tabular}{|c|c|c|c|}
\hline City & Neighboorhood & Numberof Houses & Numberof Samples \\
\hline \multirow{3}{*}{ Santo Estevão } & Alto do Porrão & 568 & 57 \\
\cline { 2 - 4 } & Mutirão & 400 & 40 \\
\cline { 2 - 4 } & Pau de Vela & 469 & 47 \\
\hline
\end{tabular}

Source: Elaborated by the authors, 2013.

For research's development, it was used the random sampling. Crespo $^{6}$ says that: This type of sampling is equivalent to a lottery draw. In practice, the random sampling can be carried out by numbering population from 1 to $\mathrm{n}$, and, through a random mechanism, it is drawn k numbers from the sequence which will correspond to the elements pertaining to the sample.

Therefore, in application's implementation, the houses were chosen according to a draw of their numbers. Some authors consider that a representative sample, depending on its size, must encompass a population's permanent percentage, approximately $10 \%$ to $20 \%$. Then, 144 applications were implemented in the three examined areas, what resulted in a total of $10 \%$ from the domiciles drawn to participate of the research.

\section{Data Analysis and Spatialization}

The data obtained through the application were organized and tabulated. Then, a basic statistical analysis was implemented to obtain the average and percentage of houses attended or not by the sewage system. After the data statistical analysis, graphics and Tables were generated for a better viewing of the tabulated information. In search of finding the data percentage, the simple rule of three was made. However, there is a mean to find percentage's results through the simple arithmetic mean. According to Crespo, ${ }^{6}$ the arithmetic mean is the quotient of the division from the addition of variables' values for their number, according to the equation: $\mathrm{x}^{\perp-}$ $=\left(\Sigma \mathrm{x}_{1}\right) / \mathrm{n}$, where $\left\{\mathrm{x}^{\perp-}=\right.$ Arithmetic Mean

$$
\begin{aligned}
& x_{1}=\text { variable vaules } \\
& \sum x_{1}=\text { Total addition of the variable values } \\
& \eta=\text { Total numbers of values }
\end{aligned}
$$

The Tables and graphics of research were generated from the simple rule of three's results.

For the production of maps, field's technical visits were done in order to geo reference spatially the location coordinates of examined areas. Furthermore, the Municipal Department of Works had also provided some maps for a better viewing of the area, and some photographs were taken to conceive the sanitation conditions of houses together with the collected information from the applications. Maps' elaboration was implemented in ARC GIS 10 and SPRING 4.3.3 software.
In the survey, the analysis of particular patterns was made in order to estimate the disease's frequency in the investigated areas. According to Câmaraand Carvalho, ${ }^{7}$ the analysis of particular patterns "are defined as a collection of points unevenly spread in a land, whose localization was caused by a stochastic mechanism". A simple alternative to analyze the behavior of points' patterns is through the estimative of the particular intensity of process in all the evaluated region. ${ }^{7}$ The estimation is calculated through interpolation from several methods as kriging, tendency surface, local models of regression and kernel estimation. When these techniques are applied to a pattern of particular events, they originate a map of intensity's boundary estimated in the investigated area.

The method used for research's development was the kernel estimation, an interpolator that enables the event's intensity estimation in all the area, and the frequency of diseases in Alto do Porrão, Mutirão and Pau de Vela, even in regions where the process did not produce a real occurrence. The quartic kernel estimation, the model adopted by SPRING app, was used to obtain an intensity estimative from the pattern of points.

\section{Results and Discussion}

\section{Destination attributed to waste produced in Santo Es- tevão's houses - sewer collection system and septic and black cesspools}

Human waste can be the conduit of pathogenic germs from many diseases (infectious diarrhea, typhoid fever, amebiasis, schistosomiasis, tapeworm infection, among others). On account of an inadequate sanitation service or a lack of health education, a huge portion of population throw waste directly on the soil, what can create a proper environment for many diseases' transmission. The Sanitary Sewer Manual ${ }^{8}$ points out that in order to prevent diseases' transmission caused by sanitary sewage, it is necessary to build toilets with a hydric conduit connected to a public system of sewer and a proper final destination. However, most of times this recommendation is difficult to comply mainly because of economic reasons. Generally, peripheral areas are those that suffer most with this situation and with the negligence from governmental authorities.

Domiciles usually have bathrooms, a sanitary structure of great importance to the environment healthiness maintenance and also to human's health keeping. Through the bathroom, the waste must 
be carried to an appropriate sewer system, either collective or individual. Figure 3 presents the domiciles of the urban perimeter from Santo Estevão's city that have bathrooms of exclusive use to residents. Houses that have bathrooms for residents' use are located next to the city's central area, illustrated by the darker colors in the map. In Alto do Porrão, a significant number of domiciles have bathrooms. While Mutirão, for being a recent area in the city, also have a reasonable number of bathrooms for each resident, and more than
200 houses have a sanitary structure (bathroom). In Pau de Vela's area almost all houses have a sanitary structure, an important element for the non-proliferation of diseases. It is also observed in Figure 3 that areas with low number of bathrooms have a larger concentration and/or presence of diseases. It is also verified that both Mutirão and Alto do Porrão have a larger percentage of people infected by diseases that can be associated to an inappropriate sewer system, which means a lack of a proper sanitary structure.

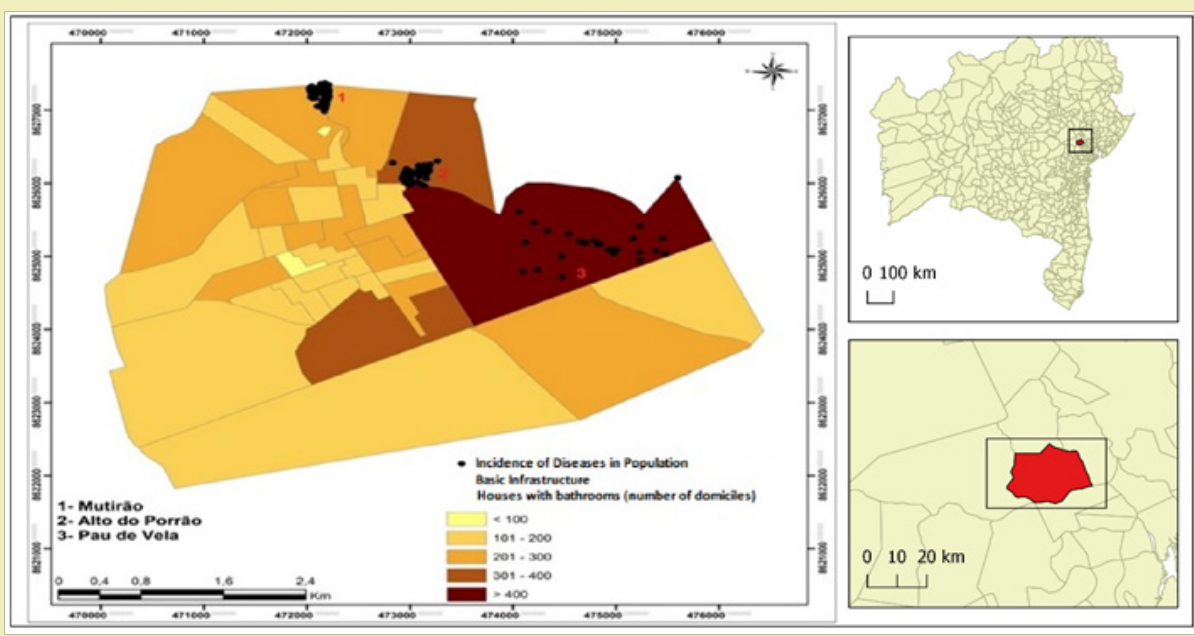

Figure 3: Domiciles in the Urban Area of Santo Estevão with Bathrooms and Incidence of Diseases on the Examined Areas that Can Be Associated to an Inadequate Infrastructure.

Source: IBGE, 2010; Bahia, 2003. Elaborated by CARELLI, L., 2014.

Figure 4 illustrates the areasfrom Santo Estevão'surban perimeter that do not have bathrooms for residents' use and incidences of diseases that can be associated to an inappropriate infrastructure. It is noticeable in Figure 4 that areas without bathrooms are those situated further from the city's central area. Thus, people who live there have to use other means to waste's disposal, and many times it is an open-air disposal, what contributes for people's disease transmission, besides it pollutes the soil and the water resources.

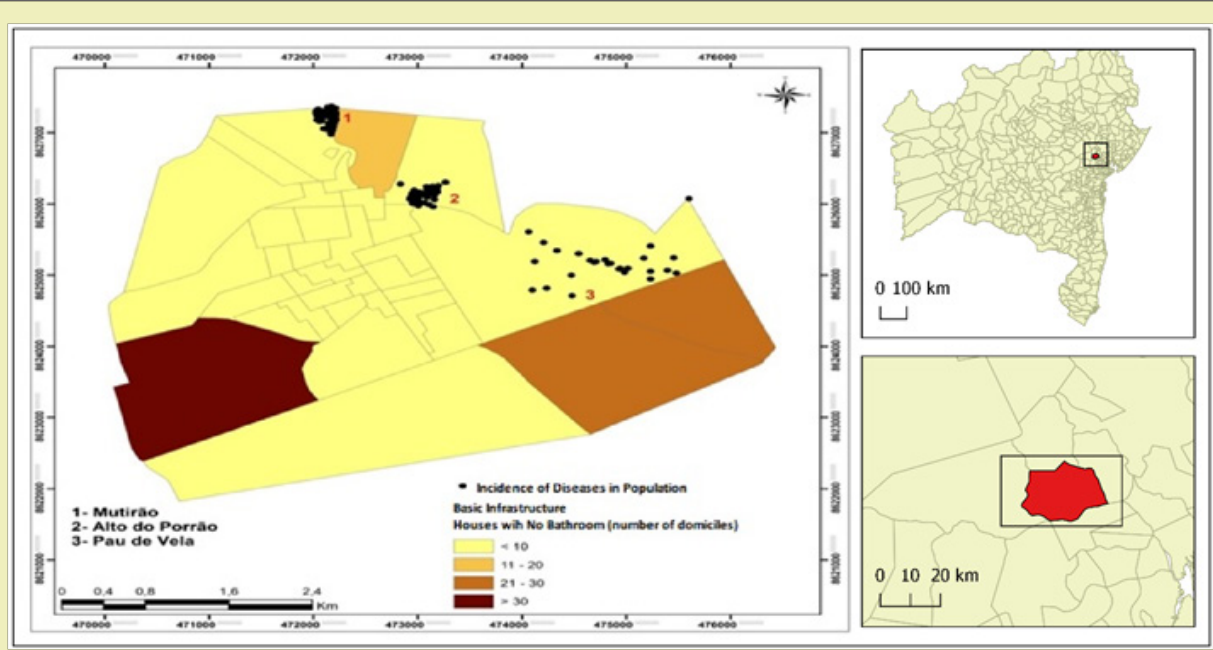

Figure 4: Domiciles in Santo Estevão's Urban Area Without Private Bathroom for the Residents. Source: IBGE, 2010. Bahia, 2003. Elaborated by CARELLI, L., 2014.

In Alto do Porrão and Pau de Vela, a few of the domiciles do not have bathrooms. On the other hand, in Mutirão the number of houses with no private bathroom is higher. Despite of having the lowest number of residences, above eleven of them do not have a sanitary structure. And still according to the acquired data, the population in Mutirão often use an abandoned area or vacant lotas bathrooms. GUSMÃ ${ }^{10}$ considers that these practices can cause a cycle of pollution among the environment, epidemiological vectors and human beings. Unfortunately, many cities do not count with a public system of sanitary sewage to attend its population's demand 
yet, that is why many people resort to other options, even when it is not the safest. In Santo Estevão's city, only Mutirão, while it is a recent area, counts with a public collection system. In Table 2 it is

Table 2: Destination of the Produced Waste in the Examined Areas.

\begin{tabular}{|c|c|c|c|c|c|}
\hline Areas & Septic Cesspool (\%) & Black Cesspool (\%) & Dry Cesspool (\%) & Collection Network (\%) & Other (\%) \\
\hline Alto do Porrão & 0 & 67 & 0 & 0 & 33 \\
\hline Mutirão & 0 & 0 & 0 & 98 & 2 \\
\hline Pau de Vela & 49 & 51 & 0 & 0 & 0 \\
\hline
\end{tabular}

Source: Elaborated by the authors from the collected data in research, 2013.

In Mutirão, approximately $98 \%$ of residents use the public sewage system, however, they complain about the precariousness from the service and about the high fees charged for it. Only $2 \%$ of population, with no private bathroom, are not attended by the Company of Water and Sanitation from Bahia state. Generally, they dispose the produced waste in avacant lot. The lack of public investment together with economic issues often foster a favorable condition to people search for improper alternatives to heal this situation; in the case here discussed, the sanitation matter. This feature reflects on areas that do not count with a public collecting system and have to use septic and black cesspools. From Alto do Porrão's evaluated houses, it was verified that in $67 \%$ of them the residents use black cesspools, what brings serious issues, mainly for people's health. Besides the risk of diseases, this practice can cause deep trouble to the environment, once the inappropriate building of cesspools illustrated the destination of the produced waste in the domiciles of the examined areas. can pollute the soil and the water resources. About $33 \%$ of the domiciles use some illegal network of public sewer. According to residents, this plumbing has as source a public network derived from the City Supply Center, a storm water collection system that carries the waste of a flea market. Another area with a high number of cesspools is Pau de Vela. With regard to the sewer's means of final destination from this area, the black cesspools respond to about $51 \%$ of houses, while the septic ones respond to $49 \%$ (Table 2). In Figures 5 and 6 it is noticeable the final destination from the waste produced in the visited houses. What is worse is that a great percentage of population are already accustomed with cesspools' existence, while there are those who say that the connection with the public network is not attractive, even if it was offered, because of economic conditions.

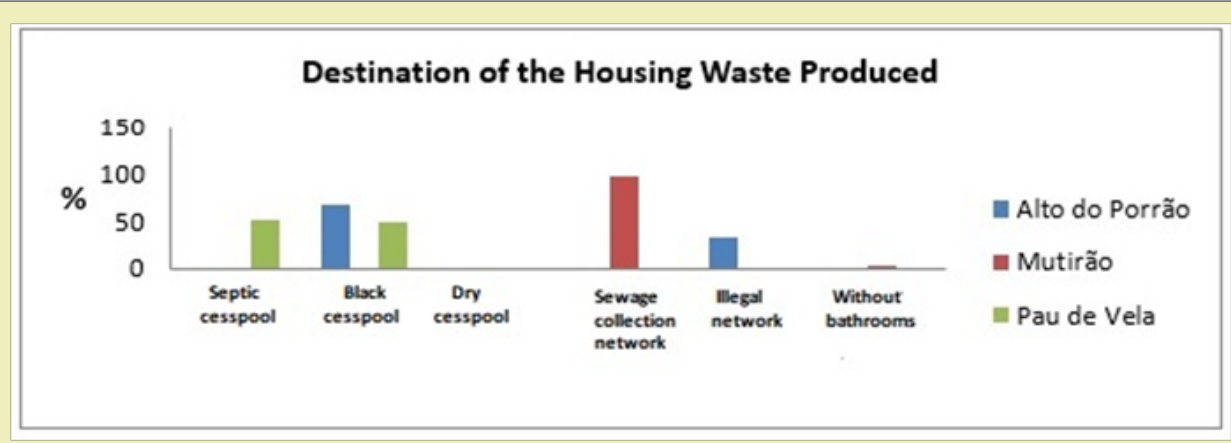

Figure 5: Percentage of the Final Destination of the Produced Waste in the Evaluated Areas' Domiciles Source: Elaborated by the authors from the collected data in research, 2013.

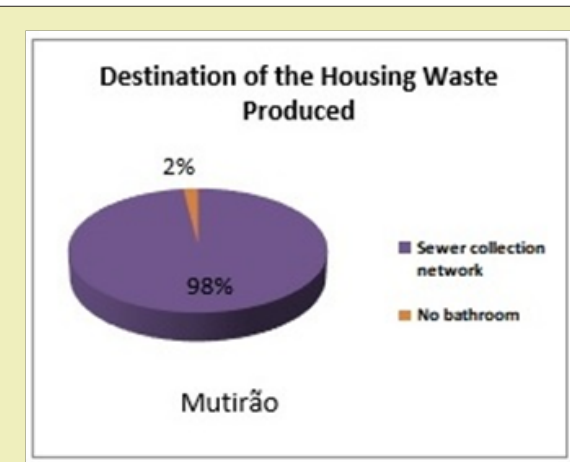

(I)

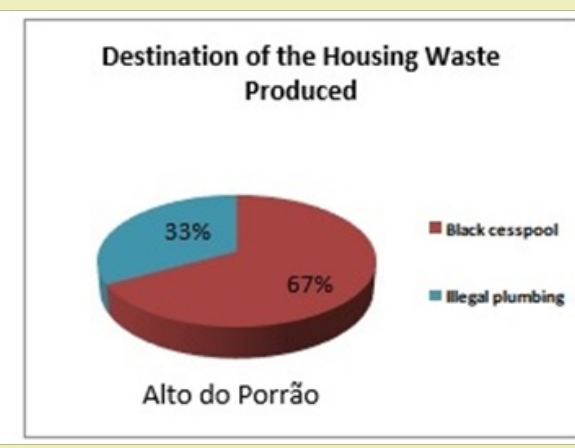

(II)

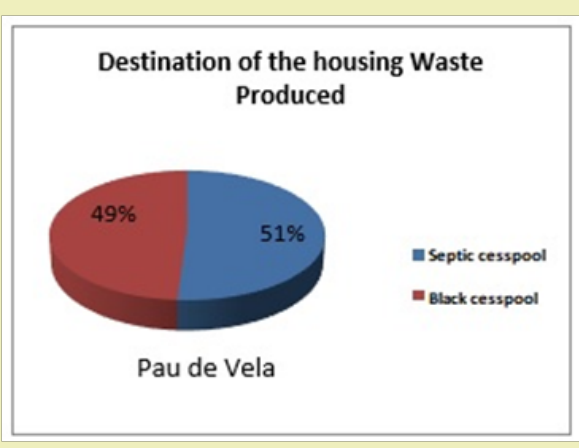

(III)

Figure 6: Individual Percentage of the Final Destination of the Waste Produced in Mutirão (I), Alto do Porrão (II) and Pau de Vela (III). Source: Elaborated by the authors from the collected data in research, 2013. 
In Table 3 it is illustrated the percentage of population by neighborhood that are supportive and against the public sewer collection network.

Table 3: Percentage of Population from the Evaluated Areas that Intend or not to Connect with the Public Sewer Collection Network.

\begin{tabular}{|c|c|c|}
\hline Areas & Yes (\%) & No (\%) \\
\hline Alto do Porrão & 88 & 12 \\
\hline Mutirão & - & - \\
\hline Pau de Vela & 55 & 45 \\
\hline
\end{tabular}

Source: Elaborated by the authors from the collected data in research, 2013.

Mutirão was the one area where there were not registered values, because it already counts with a public sewage system. Then it was not necessary the questions' application to the residents in research. Pau de Vela is the area where people are most resistant in doing the connection with the public sewer collection network, when it is implemented: in $45 \%$ of the houses, the answer was negative. According to Martins,3 in order to have a more pleasant and healthier environment with the diseases' prevention and control, it is necessary avoiding the pollution of soil and sources of water supply; stopping the contact between vectors and fecal matter; providing the establishment of hygienic customs to population; promoting comfort; and attending to a critical sense. Therefore, in search of avoiding human contact with excrements, it is necessary the implementation of correct sanitary solutions to establish its destination, and the public collection network would be the most adequate in this case. However, when the service is not provided, it is necessary finding alternative means that reduce the impacts to the environment and to people's health, taking actions to avoid the disposal of waste on soil and ditches, or directly in water or badly constructed cesspools.

\section{Main issues related to black and septic cesspools detect- ed in areas of Alto do Porrão, Mutirão and Pau de Vela}

Many issues are caused by the bad conduct of human waste produced, bringing the diseases' occurrence. In order to minimize these sanitary problems, it is necessary the building of toilets with hydric conduct connected to a public sewer system. ${ }^{8}$ However, in most of Brazilian cities, the houses do not have toilets connected to a public sewer system yet, and instead of that there are septic or black cesspools. The black cesspools are conduit of contamination to soil and groundwater. Still in other cases, the houses do not have any mean of sewage, and the waste is directly thrown on soil or water bodies.

The fact of a residence owns toilets connected to the public sector of sewer system or to another alternative mean of sewage does not imply that the final destination from waste have an adequate conduction. The maintenance of sanitary sewage systems, the public one or the cesspools, must occur with frequency to keep the good operation, in order to prevent environmental and people's health disturbance. In accordance with the analysis of applications used in the evaluated areas, some issues were detected in relation to the usage, maintenance or no maintenance, and cleaning of black or septic cesspools. Some disturbance was reported, such as bad odor, clogging, leaking, among others. In Alto do Porrão, 65\% of the interviewee said do not have problems with their cesspools, approximately $11 \%$ said to smell bad odor from cesspools, and $4 \%$ of them declared that cesspools are often leaking. In Pau de Vela, the issues related to cesspools were bad odor (19\%) and clogging (11\%); the great percentage from population declared having no problems (70\%) (Table 4, Figure 7).

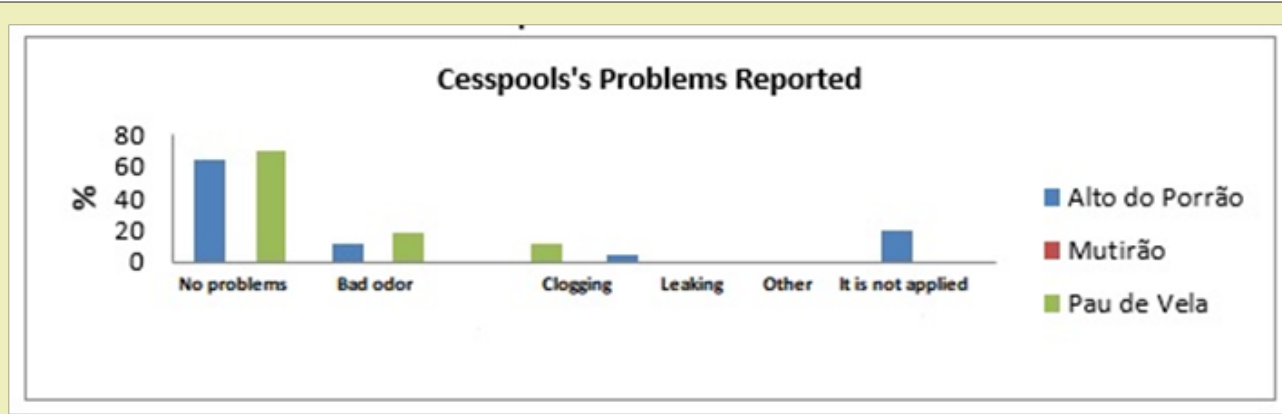

Figure 7: Percentage of the Problems Reported in the Survey's Areas with Black and Septic Cesspools Use. Source: Elaborated by the authors from the collected data in research, 2013.

Table 4: Main Issues Detected with Black and Septic Cesspools Use.

\begin{tabular}{|c|c|c|c|c|c|c|}
\hline Areas & No Problems (\%) & Bad Odor (\%) & Clogging (\%) & Leaking (\%) & Other (\%) & $\begin{array}{c}\text { It is not Applied } \\
(\%)\end{array}$ \\
\hline Alto do Porrão & 65 & 11 & 0 & 4 & 0 & 20 \\
\hline Mutirão & 0 & 0 & 0 & 0 & 0 & 0 \\
\hline Pau de Vela & 70 & 19 & 11 & 0 & 0 & 0 \\
\hline
\end{tabular}

Source: Elaborated by the authors from the collected data in research, 2013. 
Mutirão did not report problems related to cesspools, once it is the only one that has a public sewer system. However, despite of the service offering by the Company of Water and Sanitation from Bahia state, there are complaint from residents because there is not a regular maintenance of it. According to residents (Figure 8), when a clogging or sewer leaking happens, it takes days or even weeks to solve the problem, and people get at the mercy of this situation meanwhile.
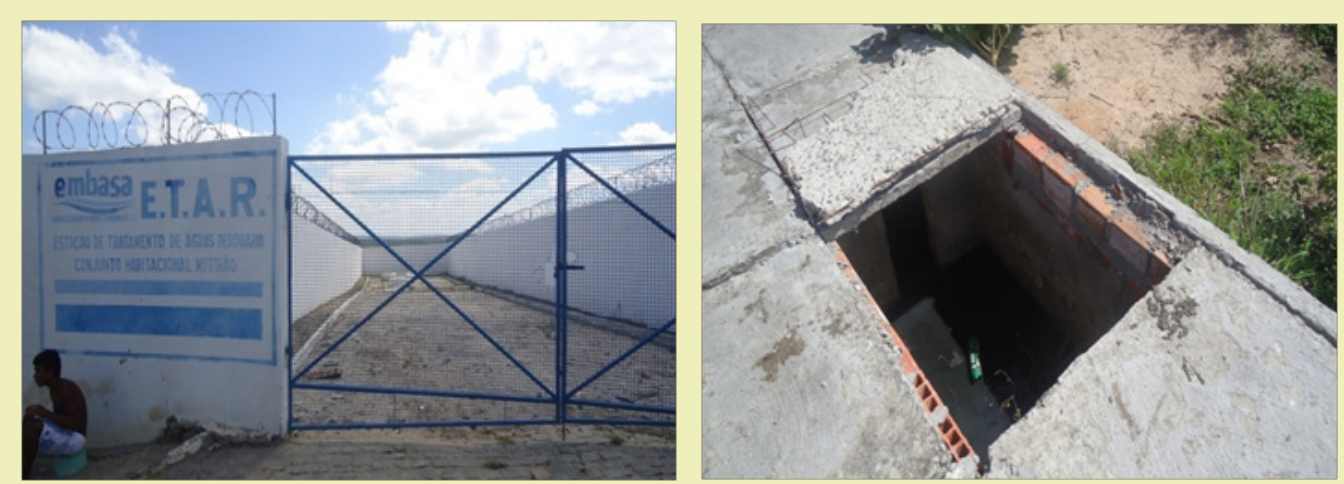

Figure 8: Company of Water and Sanitation from Bahia State Treatment Station in Mutirão

Source: The authors, 2013

The negligence from the Company of Water and Sanitation from Bahia state in the maintenance of the public sewage can cause accidents with the children's access to the opened sewage boxes (Figure 8II). In addition, people also contribute with sewer clogging when throw large-sized objects into it. The amount of diseases caused by an inadequate destination of human waste is huge. The main diseases are: hookworm infection, ascariasis, amebiasis, cholera, diarrhea, dysentery, schistosomiasis, strongyloidiasis, typhoid fever, paratyphoid fever, salmonellosis, taeniasis and cysticercosis. The transmission of diseases can occur by direct contact from skin to soil contaminated with helminth larvae, derived from fecal matter of parasite's carriers. FUNASA establishes that:

[...] the fecal matter of a sick man, carrier from hookworm infection and strongyloidiasis, contains parasite's eggs that, once under soil, hatch and liberate larvae; they wait for the opportunity to penetrate the skin of other person, moving to his/her intestine after a long way through other organs.8

Some actions can be taken to avoid diseases caused by the poorly sewage use. Among them, it can be mentioned: the use of toilets to prevent soil and surface water's contamination, fruits and greens washing with potable water; well-washing of hands before handling withfood, food's protection and elimination of the focus of disease's spread. In the evaluated areas, the diseases that can be associated to an inadequate sewage system were amebiasis, cholera, dysentery and schistosomiasis (Table 5). Among the reported diseases, the one that obtained the highest index was dysentery, attending all the evaluated areas. In Alto do Porrão and Pau de Vela, the dysentery values did not go beyond $50 \%$ of residents, while in Mutirão, 75\% of inhabitants declared that already had dysentery. What stands up is that Mutirão is the only area from the city to have a public sanitary sewer system, despite of its unsatisfying conditions and lack of maintenance, what brings population's disturbance and disease's spread.

Table 5: Detected Diseases in the Evaluated Areas that Can Be Associated to an Inadequate Sewage System.

\begin{tabular}{|c|c|c|c|c|}
\hline Areas & Amebiasis (\%) & Cholera (\%) & Dysentery (\%) & Schistosomiasis (\%) \\
\hline Alto do Porrão & 2 & - & 39 & - \\
\hline Mutirão & 17 & - & 75 & 3 \\
\hline Pau de Vela & 2 & 2 & 45 & 2 \\
\hline
\end{tabular}

Source: Elaborated by the authors from the collected data in research, 2013.

The lack of practical steps to sanitation and health education results in a background where a huge percentage of population throw their waste directly in soil or hydric sources, what promotes favorable conditions to disease's transmission. It is a responsibility from government to formalize more effective public policies that ensure people's life quality. The public system of sewage has to be a priority, it will not work just as a system to be installed, it is essential having the proper maintenance of it.

\section{Conclusion}

Several issues were detected in relation to sanitary sewage from the examined areas (Alto do Porrão, Mutirão and Pau de Vela).
The systems of sewer were considered inadequate and/or inefficient and the cause of a bad life quality to people. With respect to sanitary conditions of the examined areas, the biggest portion of people use bathrooms. Alto do Porrão is the area where most of houses have bathrooms with private use of sanitary structure, compared to the other two areas. The houses with bathrooms in Alto do Porrão and Pau de Vela allocate the major part of their waste to cesspools (black and septic ones), a damaging practice that can result in soil's contamination, besides of polluting the underground water, harming animals and spreading diseases among residents. In addition to the issues already mentioned, bad odor and leaking are very typical in the houses. Despite of being attended by the public 
sanitary sewage, Mutirão also goes through disorders in relation to the service provided, once it is offered but with no maintenance. In order to reduce the impacts of sanitary sewage, it is essential to offer the public service for all population, paying attention with a regular maintenance of system and an orientation to residents about how important is having access to this resource. Nevertheless, it is responsibility from public authorities to make people's access to the service a priority, always searching for means that contribute and reduce the values of collected fees by considering the economic background of residents.

In search of easing the sanitary sewer situation and improving people's life quality, some actions could be taken:

- Public sewer system installation with a fair tax for population;

- Regular maintenance of public sanitary sewer system;

- $\quad$ Building of cesspools, preferably septic ones, in appropriate areas situated far from cisterns and wells;

- More effective public policies to attend people's demand in relation to the sanitation as a whole;

- Organization of neighborhood's urban areas in order to have a better planning and management, besides of simplifying the data purchase in further researches;

- Investing in more consistent public policies is a governmental responsibility and it must contribute to a good sanitation's working, especially aiming at people's life quality and the assurance of a healthier environment, according to Law No. 11,445, in chapter VI, article 29, paragraph 1 , subsection II, that points out people's access to public sanitation system, mainly in low-income locations.

\section{Acknowledgments}

None.

\section{Funding}

None.

\section{Conflicts of Interest}

Author declares that there is no conflict of interest.

\section{References}

1 BRASIL. Brazilian Institute of Geography and Statistics (IBGE). Coordination of Geography. Sanitation Atlas. Rio de Janeiro: IBGE, 2004.

2 Roque, Odir C. Education for Quality of Life in View of Environmental Sanitation. In: PDBG. Subprojeto de Educação Ambiental, módulo IV. Rio de Janeiro: UERJ, 2004

3 Martins MJ. Esgotamento Sanitário. Universidade Federal de Minas Gerais, 2012.

4 Brazilian Institute of Geography and Statistics (IBGE). Ministry of Planning, Budget and Management/Brazilian Institute of Geography and Statistics. Sanitation Atlas 2011.

5 Santana, Judith Sena da Silva e Nascimento, Maria Angela Alves do Nascimento. Pesquisa: Métodos e técnicas de conhecimento da realidade social. Feira de Santana: Universidade Estadual de Feira de Santana. 2010.

6 Crespo AA. Easy Statistics. Publisher Saraiva. São Paulo. 2009.

7 Câmara G, Carvalho MS. Análise de Eventos Pontuais. Brasilia: EMBRAPA. 2004.

8 National Health Foundation. Sanitation Manual. Brasilia. 2006.

9 Gusmão, Ozineide Silva. Sanitation in an Environmental Protection Area: Diagnosis and Spatialization of the Impacted Areas in the APA of Lago do Pedra do Cavalo/BA. Feira de Santana, 2008.

10 Engineering and Projects. Sanitary Sewage Manual. Technical Guidelines. Monte Santo de Minas. Minas Gerais. 2004. 